\title{
INFLUÊNCIAS DO MARKETING \\ POLÍTICO NA FRANÇA NOS ESTUDOS \\ CONTEMPORÂNEOS DO BRASIL
}

\section{INFLUENCES OF POLITICAL MARKETING IN FRANCE IN CONTEMPORARY STUDIES OF BRAZIL}

\author{
ADOLPHO QUEIROZ \\ CALDAS, FABIO CIACCIA ROdRIGUES; CASTRO, ANA CAROLINE; \\ CEROZZI, WILLIANS; CUNHA, JORGE VIDIGAL; GAMAS, MARIA HELENA; \\ GARCIA, Paulo Roberto Salles; MACEDO, Roberto Gondo; \\ MANHANELLI, CARLOS; NASCIMENTO, ANDERSON RAFAEL BARROS DO; RAMOS, \\ ThaIlLISSA ANDARA; ROCHA, DANIELA; ROSA, PAUlo CEzar \\ Adolpho Queiroz é Doutor em Ciências da Comunicação pela \\ Universidade Metodista de São Paulo, onde atua no programa de \\ pós-graduação em Comunicação.É presidente da POITICOM, \\ Sociedade Brasileira dos Pesquisadores e \\ Profissionais de Comunicação e Marketing Político \\ Alunos do Programa de Pós-Graduação \\ em Comunicação da UMESP (mestrado e/ ou doutorado)
}

\section{RESUMO}

O presente artigo explana cronologicamente momentos marcantes da história da propaganda política na França, desenvolvido pelos alunos do Programa de Comunicação Social e Propaganda Política Stricto Sensu da Universidade Metodista de São Paulo,na disciplina de Marketing Político Internacional. A França no viés de comunicação política apresenta significativas manifestações de estratégias de comunicação de massa, seja na forma de interação com o reinado de Luis XIV até as eleições de 2007 com Nicolas Sarcosy para presidente. O principal objetivo do trabalho foi de transitar por autores especializados em comunicação política francesa, como Domenach, Burke, Quintero, Séguelá, Charaudeau, Schwartzenberg, dentre outros, e apresentar um cenário de questões contemporâneas acerca do Marketing Político Francês. Do ponto de vista metodológico foi desenvolvida ampla revisão de literatura sobre o assunto, extensiva ao panorama contemporâneo através de pesquisa nos sítios da Internet.

Palavras-chave: Comunicação Política, Marketing Político, Eleições na França

\section{ABStract}

This article explains chronologically moments in the history of political propaganda in France, developed by the students of Social Communi 
cation and Advertising Policy stricto sensu of the Methodist University of Sao Paulo, the discipline of Political Marketing International. France in the bias of political communication has significant manifestations of strategies for mass communication, whether in the form of interaction with the reign of Louis XIV to 2007 elections with Nicolas Sarcosy for president. The main objective of this work was carried forward by authors specializing in French political communication, as Domenach, Burke, Quintero, Séguela, Charaudeau, Schwartzenberg, among others, and present a scenario of contemporary questions about French Political Marketing. From the methodological point of view was developed comprehensive review of literature on the subject, extending the contemporary panorama through research on the Internet sites.

Keywords: Communication Policy, Political Marketing, Elections in France

\section{Introdução}

A propaganda política na França apresenta relevantes aspectos com relação à imprensa e a propaganda, principalmente no que tange a viés políticas. $\mathrm{O}$ século XIX do ponto de vista jornalístico é o período em que a imprensa atinge a sua plenitude, com as inovações tecnológicas; organização empresarial e financeira; aumento das tiragens dos periódicos, e a influência política.

Do ponto de vista da história da Propaganda o ritmo de evolução é diferente, nesse período, houve três grandes saltos qualitativos: as transformações da comunicação e da política na Idade Moderna, as revoluções atlânticas, principalmente a Revolução Francesa e o final napoleônico, aparição da propaganda científica, que acontece no século $\mathrm{XX}$, com a segunda guerra Mundial (e a Revolução Russa).

Dentro de uma perspectiva geral, a Historia da Propaganda, Quintero (1990) salienta que embora existisse a propaganda política e os Estados se ocupassem dela não houve, no século XIX, um salto qualitativo relevante. Entretanto, os progressos da comunicação abrem novos caminhos à propaganda, e os grandes processos de transformação política e social do século geram uma grande atividade propagandística, principalmente de oposição.

A França pós-napoleônica tenta se recuperar das convulsões que vivenciou durante vinte $\mathrm{e}$ cinco anos. Com a monarquia de Luís Filipe são introduzidas medidas liberalizadoras. A liberdade de imprensa é efetiva. Iniciou a expansão colonial francesa a procura de prestígio para o seu regime que estava muito isolado das demais monarquias européias.

Mas, o rei burguês foi incapaz de organizar uma propaganda sistemática e eficaz. Os bonapartistas conspiravam contra ele; a opinião pública republicana crescia, assim como o movimento operário. 
Com efeito, a luta contra o regime da Restauração por toda a Europa dá lugar ao conjunto da propaganda liberal e nacionalista com a imprensa, as sociedades secretas e as intentonas revolucionárias. As revoluções de 1820,1830 e de 1848 foram, sem dúvida, marcos na história da propaganda nacionalista. A onda revolucionária de 1848 significou o eclodir definitivo da propa $\neg$ ganda democrática incubada na Europa da Restauração.

Já no próximo governo, da nova República, desde o primeiro momento existiu uma clara atividade propagandística. Foram recuperados velhos símbolos revolucionários. $\mathrm{O}$ incipiente movimento operário queria negar a bandeira tricolor para substituíla pela nova bandeira vermelha. O primeiro governo da República estava consciente da necessidade de se criar uma opinião pública favorável depois de longos anos de monarquia.

Assim, uma circular de 12 de Março de 1848 informava do seguinte os comissários da República: «É necessário que não tenhais ilusões sobre a situação do país: os sentimentos republicanos devem ser vivamente excitados [...] as eleições devem ser a vossa grande obra, devem ser a salvação do país [...] a educação do país não está feita, sois vocês quem a deve orientar [...] que o dia da eleição seja o triunfo da revolução.»

A propaganda política nos grandes Estados, na França do Segundo Império, está debilitada, e «Napoléon le Petit» tenta ressuscitar os mitos do seu tio, mas os governos são incapazes de manipular a opinião pública. As Campanhas propagandísticas são levadas a efeito, para criar uma opinião favorável às várias intervenções militares do Segundo Império no exterior. Mas, o fracasso de algumas delas, acabam por ter resultados negativos ao prestígio do imperador.

Todos os governos Franceses desde 1892 apóiam a propaganda anti-germânica. O anti-semitismo ganha carta de alforria. O exército é utilizado como meio de propaganda em dois sentidos: como continuador da tradição nacional e como instrumento da vingança. Foram criadas organizações privadas de propaganda nacionalista ou agrupamentos patrióticos, como a Ligue des $\mathrm{Pa}$ triotes (1882) cuja finalidade era a «organização de educação militar e patriótica através do livro, da ginástica e do tiro»».

O movimento operário, considerado um novo fenômeno político, faz da propaganda uma arma fundamental para o seu desenvolvimento. Os sindicatos e os partidos políticos operários introduziram nos sistemas capitalistas um novo tipo de propaganda, sistemática, constante e concebida a longo prazo (educação e consciência de classe) e de modo mais imediato (greves, mobilizações concretas e projetos revolucionários). O Manifesto do Partido Comunista, escrito por Marx e Inglês em 1848, é um dos maiores textos propagandísticos da História. A propaganda marxista apela principalmente à razão, ao demonstrar a inevitabilidade do processo histórico que acabará com o capitalismo para criar a sociedade socialista. 
A expansão colonial das potências européias, principalmente França e Inglaterra, necessitam de uma propaganda interna e externa. A interna para justificar ante a opinião pública o esforço econômico e militar. A externa, dirigida a outros países e aos territórios dominados para facilitar a sua sujeição.

Analisando com maior detalhe, a história da imprensa está diretamente ligada à história da evolução das sociedades feudais e rurais para sociedades burguesas e urbanas. E conseqüentemente dos diferentes sistemas políticos e governos. A partir do século XV, com o Renascimento, Reforma Protestante, as grandes descobertas além-mar e o início da efervescência comercial e de trocas bancárias, surgem novas necessidades de informação.

Após a criação da tipografia e da prensa móvel por Gutenberg em 1438, em Estrasburgo, torna-se possível reproduzir em série um mesmo texto. E isso vai trazer novas formas de imprensa na França e no mundo todo.

Ao longo da história da imprensa, os governantes percebem então o poderoso veículo que é a impressa e tentam usá-la a seu favor. Essa maneira de incentivar os jornais também funcionava como uma maneira de filtrar e manipular todas as informações que chegavam ao público. Por muitos anos, e isso se repete diversas vezes na história da França, os dirigentes mantém uma relação dúbia com a imprensa. Ora dão liberdade, ora impõem a censura através de decretos, selos (os jornais só poderiam circular se tivessem o selo do rei e o rei só dava o selo para quem estivesse ao seu lado) e até mesmo a proibição do uso de certas palavras.

Na primeira metade do século XVI, pela primeira vez na França, em 1537, criam-se os cargos de censores da imprensa. Apesar do controle político, a imprensa conseguiu evoluir nos séculos XVII e XVIII. As "folhas" forneciam não apenas informações do dia a dia, mas também falavam sobre outros aspectos da vida cultural e social.

Também serviram de suporte para as idéias liberais. Como no início as gazettes funcionavam sobre o sistema de privilégio, tudo o que era publicado precisava ser autorizado por censores do governo, isso garantia uma certa estabilidade, graças à falta de concorrência. E como não podiam publicar as notícias que julgavam ser importantes, os jornais eram muito mais literários do que noticiosos.

A imprensa ganha um novo fôlego com a Revolução Francesa em 1789. Pela primeira vez, com a Declaração dos Direitos do Homem de 26 de agosto de 1789 , coloca-se em voga o princípio de liberdade de imprensa: Artigo XI: "A livre comunicação do pensamento e das opiniões é um dos direitos mais preciosos do homem: todo cidadão, portanto, pode falar, escrever e imprimir livremente, respondendo pelo abuso dessa liberdade nos casos determinados pela lei".

O período revolucionário além de dar um impulso na criação de diversos jornais e folhas (foram publicados mais de 1.500 novos títulos apenas entre 1789 e 1800), deu à imprensa um poder 
político que antes não havia. Ela enfim se torna parte do poder. Com o Golpe 18 de Brumário, o governo do Diretório foi derrubado na França sob o comando de Napoleão. E uma das primeiras decisões dele foi restabelecer o sistema de autorização prévia. Napoleão também foi um dos primeiros governantes na França a perceber o poder dos jornais e usá-lo a seu favor: "sempre que houver uma notícia desagradável ao governo, ela não deverá ser publicada até que todos estejam tão certos da verdade que se tornem desnecessários dizê-la, já que todos a conhecem".

A evolução da política geral (parlamentarismo, aumento do corpo eleitoral); o aumento da instrução do povo; a urbanização e a elevação do nível cultural das diferentes classes sociais contribuíram para o crescimento da imprensa. Bem como o barateamento dos custos de se produzir um jornal; a própria evolução técnica de fabricação do jornal, melhoria das vias de distribuição (estradas de ferro, correios, dentre outros).

No final do século XIX e começo do século XX, a imprensa já é parte da vida cotidiana das grandes cidades ocidentais. O jornal é um produto de consumo. Depois de anos de brigas entre os diferentes governos e regimes governamentais, os republicanos promulgam uma lei em 29 de julho de 1881 que assegura, a liberdade de imprensa, no regime mais liberal do mundo. Garantia a liberdade de publicação e difusão, tiravam das autoridades todos os meios de ação sobre os jornais.
A partir do fim da Segunda Guerra Mundial, a imprensa passou por grandes transformações, não apenas técnicas, mas de conteúdo e função. Agora os jornais não concorriam apenas com o rádio, mas, observava a televisão ocupar cada vez um espaço maior. A imprensa escrita perdera o monopólio da informação que exercera durante três séculos e, conseqüentemente das verbas publicitárias.

O campo informativo da imprensa se amplia, ao mesmo tempo em que cresce a curiosidade do público e a complexidade do mundo contemporâneo. Hoje podemos ver que há espaço para todas as mídias, dos jornais impressos aos jornais virtuais.

$\mathrm{Na}$ comunicação política francesa a imagem de Luis XIV torna-se obrigatória para análise de seus comportamentos e estratégias de imagem pública. Com rei de França, Luís XIV subiu ao trono em 1643 aos quatro anos de idade e reinou por 72 anos até sua morte em 1715, coleciona episódios e posturas que revelam como essa imagem foi sendo lapidada ao longo de sua vida a ponto de se tornar um mito constantemente comparado com os deuses e heróis da mitologia clássica, como Apolo e Hércules - e ser reverenciado como "nosso Deus visível" e "o mais poderoso monarca do universo", entre outros atributos a ele conferidos.

Desde o seu nascimento "celebrado pela França inteira com fogueiras e fogos de artifício, repicar de sinos, salvas de canhão e comemorado com sermões, discursos e poemas" (BURKE, 1994), parece clara a 
preocupação com a imagem real.

Mesmo que a partir de determinado momento tenha decidido governar sozinho e absoluto, Luís XIV nunca deixou de contar com conselheiros e pessoas próximas Mazarin, Chapelain, Richelieu, Rigaud, Colbert e outros que contribuíram para que sua imagem fosse cada vez mais glorificada. Isso era sendo edificado nas mais diferentes esferas da vida social, política, cultural, artística e religiosa.

Todos os seus feitos, mesmo os de menor importância eram registrados em gravuras, pinturas, retratos, medalhas (mais de trezentas), estátuas, monumentos, arcos de triunfo, além de sermões, poemas, narrativas e discursos. Artistas plásticos, escultores, pintores e eruditos permaneciam a seu serviço, sempre com a finalidade de enaltecer-lhe os feitos e as conquistas.

A presença do "rei-sol" e também chamado de Luís, o Grande nas guerras era acompanhada de historiadores e poetas que descreviam com detalhes cada vitória obtida. Também merece menção o fato de que a rotina do rei levantar-se, fazer refeições, deitarse, dentre outros era ritualizada, poder acompanhar esse cotidiano real constituía-se algo por demais importante e significativo.

Outros movimentos de Luís XIV, cuidadosamente planejados, também reforçaram a sua postura de homem forte, vigoroso, preocupado com o bem-estar de seu povo, justo, acessível, sensível às questões da arte. Valem como exemplos sua aparição no carrossel, considerado um dos mais grandiosos espetáculos públicos do reinado, em que o rei, como "imperador dos romanos", saiuse muito bem entre outros homens que, a cavalo, deviam correr em um picadeiro e realizar outras proezas; e a construção de grandes monumentos e palácios, como o de Versalhes, no qual se evidenciava a intenção de perpetuar sua imagem.

Ressalta-se o importante papel desempenhado pela imprensa oficial, como o jornal Gazette de France. Seus súditos e também os embaixadores estrangeiros, para quem Luís XIV dirigia suas conquistas, eram impactados por toda essa estratégia que tinha como norte promover a glória dele. Os monumentos, palácios e outras obras arquitetônicas ti-nham também outro públicoalvo: a posteridade.

Toda essa representação, Luís XIV cumpria muito bem esse papel, ao representar-se a si mesmo também experimentou momentos de crise, haja vista que havia discrepâncias entre a imagem oficial do rei e a realidade cotidiana. Além dos aspectos relacionados à sua aparência fisicamente era menor do que sugeriam as ilustrações e retratos, a peruca disfarçava a pouca quantidade de cabelo, dentre outros, eventos não-ocorridos eram celebrados, derrotas eram ocultadas e opositores denunciavam atributos diametralmente opostos àqueles divulgados, como ambição, falta de escrúpulo moral e de religião, tirania, vaidade e debilidades militares, sexuais e intelectuais.

O fim do reinado de Luís XIV - que coincidiu com os últimos anos de sua vida - foram mar- 
cados pelo que alguns críticos consideraram de "ocaso real". As guerras, mesmo as vitoriosas, deixaram o país endividado, a fome assolou a França no final do século, a doença abatia cada vez mais o ânimo do rei são exemplos daquele período. Entretanto, até mesmo no leito de morte, a teatralização se manteve, com o adeus do rei aos seus cortesãos e os conselhos a seu bisneto, além, naturalmente, do funeral, relatado oficialmente como de grande magnificência.

Já em outro momento histórico, a revolução francesa, assim como a inglesa e a americana, representou a tentativa, conseguida, de uma mudança da realidade existente. $\mathrm{O}$ novo governo instituído é diferente do anterior, acabou o sistema feudal e modificou a estrutura social deixando na Europa uma semente fecunda. Contudo, isso foi possível graças a uma "gigantesca e múltipla operação propagandística" (QUINTERO, 1990).

Dentro dessa operação propagandística alguns instrumentos podem ser encontrados como, por exemplo, inicialmente a imprensa periódica e os panfletos. Em seguida, foram incorporados a esses instrumentos outros como os cadernos de queixas, que eram informativos sobre a situação pré-revolução e com os debates ocorridos nos Estados Gerais, as gravuras e estampas.

Entretanto, muito além dos instrumentos, a propaganda revolucionária foi possível graças aos efeitos simbólicos que agregados permitiam a mudança de uma forma de vida antiga para outra nova. Por exemplo, o ineditis- mo de um exército formado por pessoas em torno de uma única nação foi utilizado como efeito propagador de uma outra forma de vida.

Assim como no exército as mudanças foram sentidas na vestimenta, na música, nas artes, no teatro, no linguajar e inclusive nas cores dessa nova nação (vermelho e azul - vinda do exército e branca - dos Bourbons).

Em linhas gerais a propaganda estava firmada em um novo modo de pensar que substituiu a tradição pelo progresso, o rei pela pátria e a fidelidade pela liberdade e a igualdade. Essas idéias-chave permitiram construir no imaginário popular a figura de um inimigo. Esses eram os contra-revolucionários, aqueles que defendiam o antigo regime.

Alei da liberdade de expressão nesse processo revolucionário foi uma bandeira defendida principalmente pelos citadinos do terceiro estado. O clero e a nobreza, por exemplo, eram a favor da liberdade de expressão, mas pensavam em uma certa limitação ou responsabilização para ela.

A imprensa teve uma importância relativa nesse período pelo elevado nível de analfabetismo da França dessa época. Contudo, a necessidade das notícias da revolução alimentaram o mercado para esse tipo de imprensa. Para incluir a todos foram criados clubes de leitura e leituras pública que foram importantes para a propagação de idéias e manutenção de um ideal revolucionário.

A revolução francesa só foi possível pela ampla propaganda realizada que potencializou os efeitos das novas idéias e de uma 
ainda não pode ser chamada de uma propaganda científica aos moldes do século $\mathrm{XX}$, mas já tem bem definidos seus objetivos, meios e temas. Ou seja, não era uma propaganda puramente intuitiva, pois já eram elaborados reflexões sobre o fenômeno e o meio. O resultado dessa ação deu efetivos resultados uma vez que a propaganda foi uma ação organizada e duradoura.

\section{O marketing político na França: conceitos}

A prática de estratégias de Marketing Político na França foi conceituada por representativos autores, dentre eles, é pertinente citar a obra de Domenach, cuja relevância no cenário global permitiu a fundamentação de conceitos do planejamento de comunicação política / eleitoral atual.

As principais leis apresentadas pelo autor propiciam um planejamento eficaz nas estratégias de campanha e comunicação, vale salientar neste artigo os principais conceitos abordados por sua obra na década de 60 , onde os principais modelos de análise se reportavam a líderes de massa como Benito Mussolini e Adolf Hitler.

Lei da simplificação e do inimigo único: "Em todos os domínios, a propaganda logo se empenha na busca da simplificação. Trata-se de dividir a doutrina e a argumentação em alguns pontos, os definido o mais claramente possível. O propagandista tem a disposição uma escala inteira de formulas: manifestos, profissões de fé, programas, declarações, catecismos, os quais em geral sob forma afirmativa, enunciam certo numero de proposições em texto conciso e claro" (DOMENACH, 1963).

É possível observar inúmeros exemplos no mundo moderno, do uso desta técnica, porem, separamos apenas um que se tornou conhecido em todo o mundo. I $\vee$ NY. Observa-se a simplificação da mensagem, a simbologia e o slogan identificando os pontos principais da comunicação que se pretende.

Lei da ampliação e desfiguração: A ampliação exagerada das noticias, é um processo jornalístico empregado correntemente pela imprensa em todos os partidos. No nazismo, as informações importantes jamais eram comunicadas em "bruto", ao aparecerem, já vinham valorizadas e carregadas de um potencial de propaganda.

"Walter Hagemann dá um exemplo de como a imprensa alemã apresentava uma greve nos Estados Unidos; ela não dizia "Roosevelt realiza uma arbitragem, recusado pelos grevistas", e, sim: "Os grevistas respondem a estúpida política social de Roosevelt com a recusa da arbitragem" (DOMENACH, 1963).

Lei da orquestração: A primeira condição para uma boa propaganda é a infatigável repetição. Conhecemos largamente o principio da freqüência em propaganda e é isso que Domenach nos alerta com a Lei da orquestração. "Goebbels dizia: A igreja católica mantém-se porque repete a mesma coisa há dois mil anos. O estado nacional-socialista deve agir analogamente". 
Lei da Transfusão: "Jamais acreditaram os verdadeiros propagandistas na possibilidade de se fazer propaganda a partir do nada e impor as massas não importa que idéia e não importa em que momento." A propaganda, em regra geral, age sempre sobre um substrato preexistente, seja uma mitologia nacional (a Revolução Francesa, os mitos germânicos), seja simples complexo de ódios e de preconceitos tradicionais: chauvinismo, "fobias", ou "filias" diversas.

Nesta lei fica demonstrada a importância da pesquisa na comunicação política/eleitoral, obtendo estas informações para o trabalho de detecção da opinião preponderante da população. Lei da unanimidade e de contágio: "Desde que a sociologia existe, tem-se focalizado a pressão do grupo sobre a opinião individual e os múltiplos conformismos que surgem nas sociedades".

Esta lei é a constatação e a observação de Domenach sobre as pesquisas de opinião pública, onde, para quem estuda a sério esta atividade, sabe que um grupo tende a ter unanimidade de opiniões, derivada da pressão e da opinião da maioria, contagiandose com isso.

No decorrer do processo conceitual, uma outra contribuição remete-se ao livro do autor RogerGerard Schwartzenberg, cujo objetivo se direciona em um ensaio sobre e contra o star system em política. O autor parte do princípio, que a política vai buscar no teatro inspirações para efetivar a prática do governo ser administrado por estrelas de partido, "vedetes políticas", que ao as- sumirem posições na hierarquia política obscurecem o programa e a organização, além disso, faz o espetáculo girar exclusivamente em torno de si mesma, como mera plataforma para promoção pessoal.

A primeira publicação, em 1977, está dividida em três capítulos, o primeiro, intitulado Personagens, traz a idéia de personalização do poder. Nessa etapa atribuí-se ao homem público papéis estereotipados do repertório político, procura-se projetar uma imagem heterogênea seja de Herói (Common Man), de Líder Charmoso ou do Pai da Pátria, na batalha constante de criar um rótulo, que seja a representação real ou suposta do seu perfil frente à opinião pública. Não se deve dissociar muito do real a sua imagem, porém infelizmente "pouco importa a realidade em si mesma o importante é que acreditem nesses mitos e símbolos e aceitem-nos".

Escolhido o papel, monta-se o Espetáculo, título do segundo capítulo, através de inspirações nas peças teatrais ou cinematográficas, com o objetivo de melhor confundir a arte política e o artifício. Sendo assim, os profissionais do espetáculo e da política compartilham atitudes e hábitos, o show business se desdobra num pol'business.

$\mathrm{O}$ ator político se transforma num plastic politicians manipulado pelo coordenador de mídia, afirmando com isso uma nova forma de direção de atores afim de "projetar" uma imagem atraente. Em conseqüência, da inserção desses atributos, a política se transforma em teatro de ilusão, 
aliado a um ídolo, consegue distrair o coletivo dos problemas reais através da contemplação fascinante de um "monstro sagrado a exibir emoções, por vezes sinceras, frequentemente fictícias, e sempre egocêntricas".

A comunicação de conteúdo intelectual, racional e programático cede terreno diante de uma comunicação de conteúdo mais afetivo e personalizado. $\mathrm{O}$ vedetismo no poder procura seduzir mais que convencer; encantar mais que argumentar. Induz a escolher um perfil e não uma política; imagens e não uma ideologia. Ajusta-se a "midiapolítica" ou também a "telepolítica", denominações diferentes dadas por autores que tendem direcionar a política tal como foram rebaixadas pelos meios de comunicação, não criadas, mas sim valorizadas e deslocadas por eles.

O autor relembra que não existe espetáculo sem espectadores, a personalização do poder não está apenas em quem o exerce, mas também naqueles quem a ele se submetem ou a alimentam, que se tornam cúmplice dela. No terceiro e último capítulo, denominado Público, Schwartzenberg, analisa as razões do sucesso desse espetáculo político junto ao público.

Procura-se responder $\mathrm{o}$ porquê e para quê a personalização do poder?, já que se vota a favor de uma personalidade, ou seja cuida-se da embalagem do "produto" político sem a menor preocupação com seu conteúdo, apela mais para as impressões que para as informações, mais para as emoções que para as convicções. Resultado: uma ad- ministração medíocre por falta de informações sinceras sobre os verdadeiros problemas e necessidades do eleitorado.

No fundamento conceitual, a publicação "Discurso Político" contribui com o arcabouço acadêmico com a integração de diversas áreas do conhecimento, como comunicação, psicologia, administração, entre outras ciências, para evidenciar a importância da prática discursiva no âmbito político.

$\mathrm{O}$ autor discorre sobre a relação de poder presente no anseio da massa que constrói a conjuntura social. "O sujeito-alvo é colocado em uma posição de dominado, o sujeito de autoridade em uma posição dominante e os dois em uma relação de poder. Assim, pode-se dizer que todo o ato de linguagem está ligado à ação mediante as relações de força que os sujeitos mantêm entre si, relações de força que constroem simultaneamente o vínculo social" (CHARAUDEAU, 2006).

Com relação à linguagem adotada pelos políticos, é apresentado que o ideal é trabalhar com argumentos de razão e paixão, sendo que toda a escolha é minuciosamente articulada. "Segue-se uma grande prudência na escolha das palavras, uma estratégia de emprego de fórmulas inanes, suscetíveis de agradar a maioria, ou uma estratégia de banalização do vocabulário, certamente, do emprego do vocabulário da parte adversa. Isso se verificou várias vezes nos grandes momentos de enfrentamento face a face no campo político (como durante as disputas presidenciais na França entre François Mitterrand e 
Valéry Giscard d'Estaing, em 1981; entre Mitterrand e Jacques Chirac, em 1988; entre Chirac e Lionel Jospin, em 1995" (CHARAUDEAU, 2006).

Porém, para que todas essas estratégicas sejam adotadas, o político (personagem) deve transparecer legitimidade à nação, levando sempre em conta a diferença entre ser legítimo e crível, permitindo a transmissão da idéia e imagem de credibilidade interagindo com a camada populacional envolvida.

Assim, para que o 'personagem' tenha um bom resultado nas urnas, ele deve despertar no imaginário coletivo uma correlação entre sua fala e seu comportamento, sua postura moral e ética, seu comprometimento humanístico, sempre evidenciando a certeza de que, ao chegar ao poder, seus 'aliados sociais' serão respaldados por um homem (ou mulher) que os represente e que faça por eles o que foi prometido e idealizado pelos eleitores.

Segundo Charaudeau (2006), "o político é assim conduzido implacavelmente a fazer o triplo papel de ator, de personagem e de pessoa: como ator, mostra sua imagem, na verdade, seu carisma; como personagem, desempenha plenamente seu papel de político no exercício de suas funções; como pessoa - discretamente destilada -, mostra que não é menos humano, que tem sentimentos como os demais".

Mas antes de chegar ao poder, o candidato tem que passar por um processo eleitoral e confrontar suas idéias com adversários que certamente irão querer massacrá-lo para denegrir sua imagem. É nesse momento que o político deve tomar cuidado com suas posturas e seu discurso.

A obra evidencia a importância da articulação minuciosa do discurso político, como também o entendimento dos anseios da massa. A expressão 'teatro' é utilizada para definir a postura que os políticos adotam para atrair seus eleitores, já que estes últimos buscam em seus representantes segurança, confiança e credibilidade.

\section{Marketing conttemporãneo na França}

Na contemporaneidade, várias contribuições se dispuseram relevantes, porém foram selecionadas algumas obras e análise de fatos contemporâneos que complementam o caráter de exposição cronológica objetivada pelo artigo. O livro "A vertigem das Urnas" apresenta a prática da comunicação política, feita por um dos mais renomados publicitários da França, Jacques Séguéla.

Responsável por diversas campanhas pelo mundo, do Oriente Médio à América do Sul, acredita que a publicidade tem o dever de trabalhar em grandes lutas humanitárias e políticas.

Séguéla ressalta algumas barreiras na relação entre publicidade e política, como o pouco tempo para que as campanhas sejam organizadas e a vergonha dos políticos em admitir a necessidade das ferramentas publicitárias nas disputas eleitorais. $\mathrm{O}$ autor fortalece a opinião de que os políticos não entendem 
que eleição é um ato de consumo como outros, com a diferença de não existir devolução, o eleitor tem que esperar até a próxima disputa para fazer outra escolha.

Neste cenário a publicidade deve ser vista apenas como um amplificador do que o candidato realmente é. Não lhe compete criar uma imagem falsa, pois esta não se sustentará. A eleição é ganha pelo candidato, podendo uma boa comunicação ajudar na vitória. Porém, quando a campanha é mal feita pode derrubar uma boa candidatura.

O livro apresenta dez regras que norteiam as campanhas realizadas pelo autor e segundo ele, sempre que deixou de seguir alguma, foi derrotado. São elas: vota-se num nome, não num partido; vota-se numa idéia, não numa ideologia; vota-se no futuro, não no passado; vota-se pelo espetáculo, não pela banalidade; vota-se para si mesmo, não para o candidato; vota-se no verdadeiro, não no fingido; vota-se por um destino, não por uma banalidade; vota-se num valor, não numa função; vota-se na ação, não na passividade; vota-se num vencedor, não num perdedor.

$\mathrm{Na}$ parte final do livro, o autor apresenta sua visão de como será o marketing político no futuro, neste cenário dois pontos merecem destaque: o primeiro é a importância que o relacionamento entre eleitor e político ganhará, não só durante o período eleitoral, mas constantemente, sendo valorizadas as ferramentas de marketing de relacionamento, já o segundo será o crescimento da Internet como meio de contato entre eleitores e políticos e instrumento de singular importância nas futuras campanhas.

E outro trabalho, Linda Bulik focaliza as conexões entre o jornalismo e a história por meio das mudanças, discurso jornalístico/ narrativa histórica. São analisadas as matérias de dois jornais franceses, o Le Nouvel Observateur e o L'evenement Du Jeudi.

Elouard Balladur e Jacques Chirac têm a construção de suas imagens, em torno da mudança social. Ambos os amigos de mais de 30 anos, se viram em lados opostos na iconicidade, criada pelos dois jornais. Balladur está para Louis Phellipe, como Chirac está para Napoleão Bonaparte. A disputa eleitoral entre os dois candidatos foi comparada a dois grandes vultos da história francesa. Os jornais informavam aos franceses e chamavam a atenção dos mesmos para acompanhar o desenrolar de um estilo diferente de levar a notícia, fazendo um vínculo entre a história e atualidade que está sendo contada.

A linguagem-objeto do jornalismo cede para a linguagemlinguagem. Os signos que compõem o texto remetem a um código anterior de base, de onde retira a significação. Pura metalinguagem. Sem isto, o leitor não acompanha a trama jornalística. A imprensa aproxima a família gaullista da família real.

Um importante meio de comunicação e interação política são os veículos de mídia impressa, nesse caso, em um jornal, a informação é dada de três maneiras: na organização do material do jornal, na transferência da enunciação em favor dos agentes 
da atualidade e na organização narrativa do propósito, que se fundamenta no enunciado narrativo e sobre artigos realistas, que trata menos de ter a ilusão do reproduzir a realidade do que uma produção simbólica do real.

Tétu (1997) diz que o jornal "faz acreditar". Não necessariamente acreditar nos fatos, mas no novo "real" produzido por esse ele. Véron (1981) afirma: o jornal constrói o acontecimento.

Até 1881 o poder da imprensa política ocorria sobre os debates provocados pelo jornal enquanto na atualidade esse debate aparece pela voz "dos outros" repercutida nas matérias. A organização e distribuição dos enunciados sobre a página, provocam a hierarquização da leitura. A distribuição dos assuntos no jornal é uma forma de persuasão. Nesta ótica é feita análise do Le Monde e Libération.

No Le Monde as informações são classificadas por uma normalização que não obedece a uma hierarquização natural dos acontecimentos. Os assuntos são dispostos pelas categorias do conteúdo das informações. Isso constitui um dos modos de "produzir o real". Jean Baudrillard (1970), explica que o Le Monde publica as notícias em uma multiplicidade de "esferas transcendentes, autônomas e abstratas".

Os temas são organizados por um consenso "normalizador". A leitura do Le Monde faz aparecer uma dupla organização: a sucessão linear horizontal dos títulos e seções, combinados com a organização vertical do espaço do texto. As subseções seguem hierarquia pela classificação dos as- suntos. Por esta razão parece não dar maior destaque a um ou outro assunto.

Com isso a mídia francesa (escrita, rádio e TV) utiliza o $L e$ Monde como uma referência, um modelo de informações. Somente os assuntos políticos aparecem dominados pelo acontecimento, ou parecem dizer o acontecimento. De maneira geral, o Le Monde consiste em integrar um acontecimento expressa pelo título em uma problemática existente. Não tenta produzir ou manifestar uma significação, mas sim uma referência: liga a informação à referência.

O Libération, conforme descrito por Mouillaud (1997), é uma tendência na forma de apresentar notícias. Sua diagramação parece um quadro do renascimento, onde o espaço comum para os acontecimentos é homogêneo em todos os seus pontos, seja qual for a origem geográfica e a natureza temática das informações. Como no Renascimento, atribui a figuração dos seres e das coisas. A disposição das informações no jornal é como a metáfora da "janela através da qual se vê o mundo".

O Libération dispõe as notícias numa suposta certa ordem do mundo, como sendo "um conjunto de formas reunidas". A disposição da informação faz a representação do real nesta forma. Enquanto no Le Monde a arquitetura é uma alegoria da instituição social, no Libération parece que as figuras do mundo saltam diretamente aos olhos do leitor numa ordem que parece se tornar instituidor.

A diagramação do Libération não impõe uma ordem estável. $\mathrm{O}$ 
bilidade e leitura. Neste formato as informações parecem produzir dia após dia um pequeno número de lembretes, orientam a opinião todos os dias sobre um polo como um ímã que poria ordem em uma massa.

Sua estrutura é ordenada pela presença de ritmos para aproximar os polos e conflitar a ordem. Utiliza-se de "zoom" em detalhes das imagens, destacando pontos para chamar a atenção do leitor, ou joga em plano aberto, as informações antes recortadas. Assim a diagramação não aparece como uma superfície plana, mas com profundidade, joga com próximo e distante.

No jornal, lêem-se primeiro os títulos e depois os artigos de interesse. A diagramação do Libération proporciona leitura que invoca o passar de um artigo a outro. Mouillaud considera que o Libération, parece representativo de uma tendência não só da imprensa, mas de toda a mídia.

A estrutura atual no regime francês é da consideração do voto universal, pessoal, livre e secreto, com idade mínima de 18 anos para o exercício do voto. Para a participação no processo eleitoral como candidato as respectivas idades mínimas se enquadram como sendo: municipal acima de 18 anos, presidencial e legislativo acima de 23 anos, e por último, senatorial acima de 35 anos.

No aspecto eleitoral é instituído o segundo turno em caso de necessidade, sendo o mandato de cinco anos para os cargos, exceto para o senado, onde o período do pleito são nove anos. Nas eleições proporcionais a distribuição de cadeiras é realizada obedecendo ao critério do quociente eleitoral, ou seja, o total de votos válidos divididos pelo número de cadeiras.

Nas eleições de 2007 cinco candidatos concorreram ao pleito, sendo eles Nicolas Sarcosy, ex-ministro do Interior do governo de Jacques Chirac (UMP), Sègoléne Royal do partido socialista, onde participa desde 1978, Bayrou, líder do partido da União pela Democracia Francesa (UDF), Jean Marie Le Pen, do partido da Frente Nacional (FN) e Olivier Besancenot, líder da liga comunista revolucionária.

No segundo turno, os candidatos foram Sarcosy e Royal, finalizando o processo eleitoral com vitória de Sarcosy com $53,06 \%$ dos votos válidos. A bandeira principal de ambos os candidatos foi o desemprego e o fomento de políticas públicas para o tratamento de imigrantes no país. Como marco na história política francesa, 44,5 milhões de eleitores compareceram para o processo eleitoral.

Logo após a vitória de Sarcosy, várias manifestações oposicionistas ocorreram pelo país, com foco mais acentuados na região que em 2005 ocorreram intensos combates entre imigrantes e policiais, estes hierarquicamente reportados ao até então ministro do interior Nicolas Sarcosy.

Com relação à Internet, uma pesquisa no sítio Google francês sobre o tema: "Marketing contemporâneo da política francesa" resultou, em 28 de outubro de 2007, em 927.000 páginas. Para análise e evidenciação foram utilizados apenas os 10 primeiros itens na ocorrência de pesquisa. 
É importante informar, que o serviço do sítio Google classifica os itens pelos mais acessados, desta forma, foi possível realizar uma pesquisa com caráter qualitativo, pois a incidência de acessos se relaciona com a aceitação dos respectivos conteúdos. Nos dez primeiros endereços da primeira página, quatro itens referem-se a livros, três itens à cursos, um item sobre portal para pesquisa Wikipédia, um item sobre notícias e informações e um item sobre trabalhos acadêmicos.

Com estas informações, evidenciou-se que as fontes de conhecimento sobre este assunto, utilizada pelos franceses são: os livros em primeiro lugar, seguidos de cursos.

Em um segundo momento foi efetuada uma nova busca, agora com o tema "marketing político francês". Nos dez primeiros itens, de um total de 1.960.000, o primeiro refere-se a um site sobre livros de marketing político, que quando acessado, nos remete a uma página contendo 772 livros sobre marketing politique française. Baseado nesses dados é possível apontar que os franceses que utilizam a rede digital para pesquisar este assunto encontram nos livros sua principal fonte de conhecimento.

O segundo item da página principal pesquisada foi o da Enciclopédia Livre Wikipédia. Verifica-se que a primeira e a segunda fonte são os livros e que na França os livros impressos ainda ganham dos textos virtuais.

$\mathrm{O}$ terceiro item pertence a uma empresa de negócios e tecnologia comercializados pela net "zdnet" e se refere a um artigo sobre Marketing Político. $\mathrm{O}$ número de acessos deve ser significativo para que possa estar em terceiro lugar na página sobre marketing político.

O quarto item refere-se a um artigo com a chamada de 01 de junho de 2006, intitulado o Senhor Dinâmico contra a Senhora Gentil, realizado pelo site de Bernard Huyghe - um especialista Francês em política e estratégia.

$\mathrm{O}$ quinto item refere-se a uma ficha de um livro sobre o assunto Comunicação e Marketing do homem político. $\mathrm{Na}$ sexta ocorrência, um artigo evocando o ponto principal sobre a credibilidade das informações nos noticiários públicos ou privados. O sétimo item é um artigo do partido de Sarkosy. O oitavo item oferece livros sobre a política francesa. O nono presta serviços profissionais on line sobre marketing político Francês. O décimo e último item analisado é um site especializado em venda de artigos.

Foi também desenvolvida nesta pesquisa uma visita a sites franceses de charges. Foram selecionados os sites que apresentam relação com os temas das últimas eleições francesa. As charges encontradas neles são impactantes, contendo uma dose de critica a inteligência dos dois principais candidatos: Nicolas Sarkosy e Ségolène Royal. Também fazem menção a opção sexual de cada candidato e satirizam suas propostas de plano de governo. 


\section{Considerações finais}

A análise desenvolvida sobre a temática de comunicação política propiciou uma compreensão dos comportamentos políticos e culturais da França, pois suas características atuais, como seu sistema político possui históricos que justificam esse processo evolutivo de defesa dos direitos civis e de liberdade de expressão.

A história da imprensa francesa apresentou pontos de luta pelos direitos de liberdade de expressão vivenciados em diversos momentos da história do século XIX e XX. A tipografia de Gutenberg alavanca o cenário impresso no país, propiciando de maneira gradativa uma ampliação cultural nas diversas regiões francesas.

$\mathrm{Na}$ análise da figura de Luís XIV, ao buscar construir uma imagem pública, bebeu de fontes importantes, como a de seu próprio pai, Luís XIII, e de seu tio e sogro, Filipe IV. Ambos, de modos peculiares, dedicavam especial atenção à construção de uma imagem favorável de seu governo.

Do mesmo modo, nota-se que importantes lideranças do século XX traçaram estratégias similares para a construção de imagem. Evidentemente alguns suportes são diferentes, como os tecnológicos, entretanto as semelhanças são fortes.

A obra de Domenach, desenvolvida na década de 60 contribui de maneira intensa na estruturação das diretrizes de comunicação política no mundo. Suas Leis e implantação no cenário político propicia um ferramental funcional no planejamento de comunicação política.
Schwartzenberg expõe de maneira coerente o formato de compreensão dos atores políticos quanto a credibilidade e exposição perante a população. Relembra que não existe espetáculo sem espectadores, a personalização do poder não está apenas em quem o exerce, mas também naqueles quem a ele se submetem ou a alimentam, tornando-se cúmplice dela.

No Marketing político contemporâneo, uma contribuição significativa foi a conversão em livro dos relatos de experiência de Jacques Séguelá em sua atuação no cenário político francês contemporâneo. Os profissionais de marketing político devem estar atentos às características dos eleitores, conhecer seus valores e acompanhar as mudanças.

A diversificação das ferramentas de comunicação propõe uma nova forma de comunicação entre políticos e eleitores e orientar para essas mudanças é função dos profissionais de comunicação.

Bulik foca as conexões entre o jornalismo e a história por meio das mudanças, discurso jornalístico/narrativa histórica, com a análise de matérias de dois jornais franceses, o Le Nouvel Observateur e o L'evenement Du Jeudi.

A análise dos tablóides franceses Le Monde e Libération contribuíram para o fortalecimento da aplicabilidade da comunicação impressa e digital. Os autores Jean-François Tétu e Maurice Mouillaud, consideram que nossa sociedade é feita de adaptações múltiplas, mimética, uma sociedade de empatias.

Compara o Le Monde como um grande jornal clássico onde as 
informações são publicadas por uma normalização definida pelo editor, enquanto o Libération tem uma diagramação ousada, que parece um quadro renascentista em que o leitor encontra sob um sentido a informação e o prazer, compartilha entre o sério e o não-sério, que se apresentam em outro sentido.

No sistema atual, a estrutura eleitoral francesa possui muitas próximas a do Brasil, principalmente no que tange a distribuição de cadeiras na esfera legislativa e as formas de interação de poderes, centrado no executivo. Nas eleições de 2007 , cinco candidatos concorreram a presidência e Nicolas Sarcosy saiu vitorioso em disputa em segundo turno com Sègoléne Royal.

No ambiente digital, pesquisas realizadas em sítios de busca do país, principalmente na ferramenta Google permitiram a análise que o público usuário da rede na França se interessa pelo assunto política e marketing político, pois a ocorrência apresentada nas buscar foi significativa.

\section{Referências}

ALBERT, P. \& TERROU, F.(1970) 'História da Imprensa'. São Paulo: Martins Fontes.

BAUDRILLARD. Jean, (1997). 'La société de consommation' In MOUILLAUD, M, O (1970) 'Jornal, da forma ao sentido', Brasília: Paralelo.

BULIK, L. (2006). 'Quando o Jornalismo se faz História'. Comunicação Veredas - Revista do Programa de Pós-Graduação em Comunicação da UNIMAR - Universidade de Marília - Marilia/SP, Brasil, ano 5, n 05.

BURKE, P. (1992). 'A Fabricação do Rei: A construção da imagem da imagem pública de Luis XIV'. Rio de Janeiro: Jorge Zahar.

CHARAUdEAU, P.(2006). 'Discurso Político'. São Paulo: Contexto.

DOMENACH, Jean Marie. (1963). 'A Propaganda Política', 2.ed. São Paulo: Difusão Européia do Livro.

QUINTERO, A. P. (1990). 'História da Propaganda'. Lisboa-CODEX Portugal: Planeta editora, LDA.

MOUILLAUD, M. \& PORTO, S. (1997). 'O jornal da forma ao sentido'. Brasília: Par. 15. 
SCHWARTZENBERG, R.G. (1977). 'O estado espetáculo. Propaganda, o poder da imagem' (Propaganda: L'image et son pouvour). Rio de Janeiro: Difel.

SEGUELA, J. (2007) ‘A Vertigem das urnas’. São Paulo: Tag Line. TÉTU, J.F. (1997). 'Referências e Significação: Le Monde', In MOUILLAUD, M, (1997) 'O Jornal, da forma ao sentido', Cap. 9, p 191. Brasília, Paralelo.

VÉRON, E. (1981) 'Construire l'événement’. Paris, Minuit. 